\title{
Correction to: Collaborative immersive authoring tool for real-time creation of multisensory VR experiences
}

\author{
Hugo Coelho ${ }^{1}$ (D) $\cdot$ Miguel Melo ${ }^{2} \cdot$ José Martins $^{1,2,3} \cdot$ Maximino Bessa ${ }^{1,2}$
}

Published online: 21 January 2020

C) Springer Science+Business Media, LLC, part of Springer Nature 2020

\section{Correction to: Multimedia Tools and Applications \\ https://doi.org/10.1007/s11042-019-7309-x}

In the original publication, Figs. 1 and $\mathbf{2}$ were interchange and the citation of Fig. $\mathbf{1}$ in the third paragraph of section 2.2 Authoring tools for multisensory VR experiences should be removed.

The citation of Fig. 2 in section 3.1 System architecture should be changed to Fig. 1 and the citation of Fig. 1 in the same section should be change to Fig. 2. Also, the acknowledgement is missing in the original publication.

The corrected figures and acknowledgement are presented in this erratum.

The online version of the original article can be found at https://doi.org/10.1007/s11042-019-7309-x

Hugo Coelho

hcoelho@utad.pt

1 University of Trás-os-Montes and Alto Douro, Vila Real, Portugal

2 INESC TEC, Porto, Portugal

3 Polytechnique Institute of Bragrança - EsACT, Mirandela, Portugal 


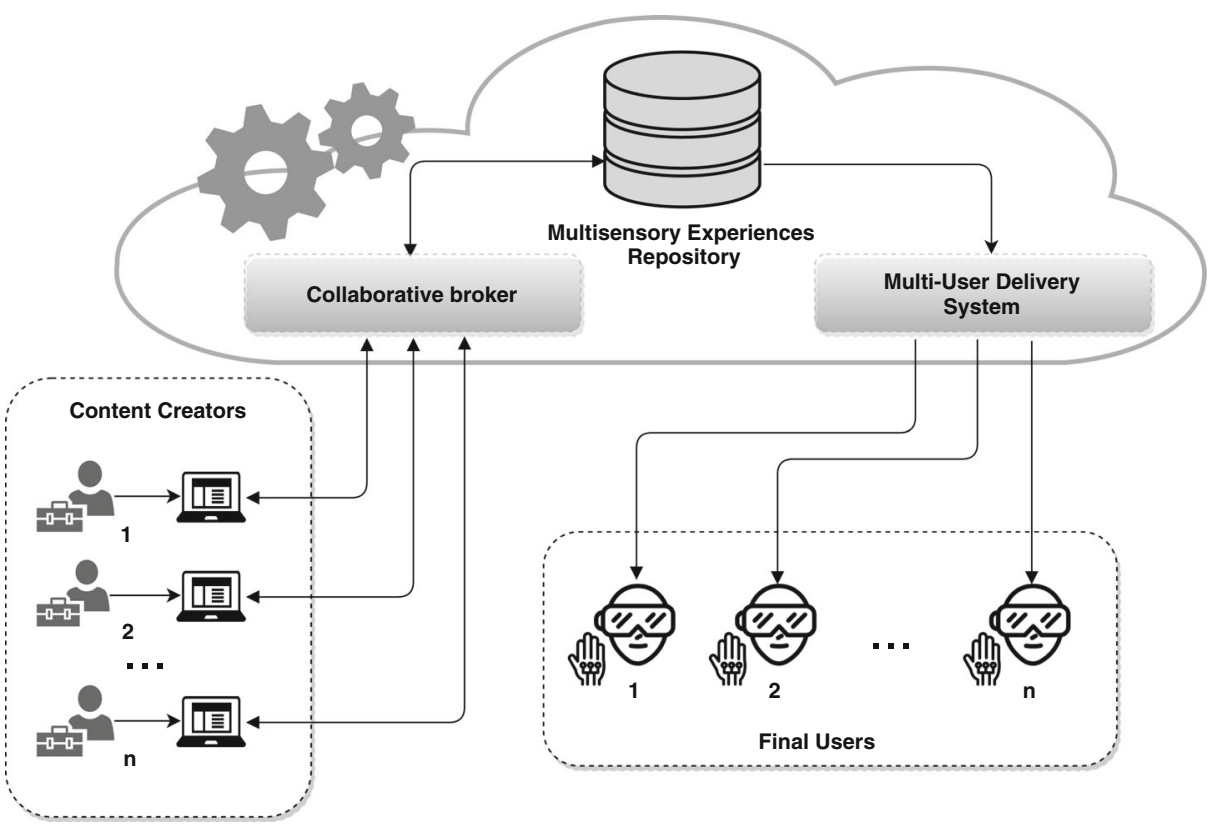

Fig. 1 Global architecture of the collaborative immersive authoring tool for real-time creation of multisensory VR experiences

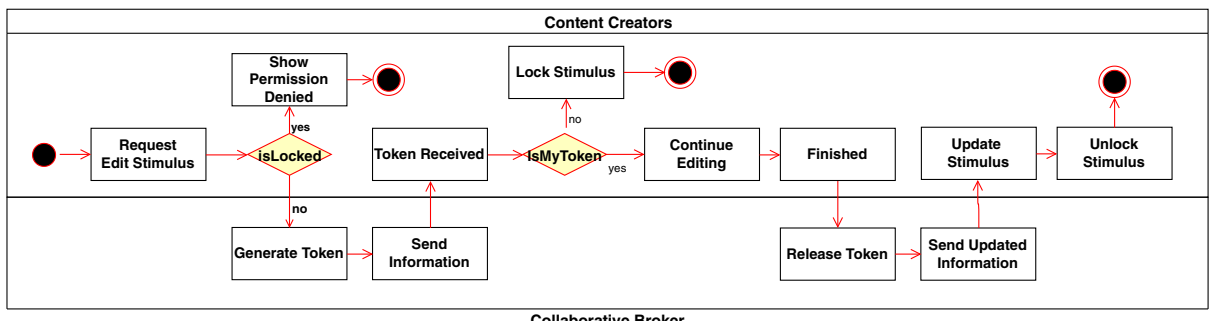

Fig. 2 Collaborative feature workflow

Acknowledgements This work was also partially supported by the project "DOUROTUR, Turismo e Inovação Tecnológica no Douro/NORTE-01-0145-FEDER-000014" financed by the North Portugal Regional Operational Programme (NORTE 2020), under the PORTUGAL 2020 Partnership Agreement, and through the European Regional Development Fund (ERDF). All the works were conducted at INESC TEC's MASSIVE VR Laboratory.

Publisher's note Springer Nature remains neutral with regard to jurisdictional claims in published maps and institutional affiliations. 